\title{
O MUNDO E AS LITERATURAS EM MOVIMENTO
}

Marilúcia Mendes Ramos

Universidade Federal de Goiás

$\mathrm{D}$

iferentemente do que em um primeiro momento a palavra possa sugerir, o hibridismo pressupõe ação. No processo de troca, os elementos de uma cultura devem ser ajustados aos da outra cultura. Os cruzamentos culturais, sejam eles no âmbito local ou a distância, não datam de hoje, assim como a tão propalada globalização. Com ela, trocas culturais vêm sendo praticadas há séculos, porém a contemporaneidade é bastante favorável aos intercâmbios porque diversas trocas culturais estão sendo efetuadas e de modo abrangente e cada vez mais veloz, sem que consigamos acompanhar essas mudanças constantes nos processos de hibridização.

Organizado em quatro grupos de reflexões, Literaturas em movimento - hibridismo cultural e exercício crítico traz parte dos produtos do Grupo de Trabalho da ANPOLL (Associação Nacional de Pós-graduação em Letras e Lingüística) de Estudos Comparados de Literaturas de Língua Portuguesa, que contribuem de forma instigadora para se pensar os intercâmbios culturais no mundo globalizado.

A discussão de conceitos formulados pela crítica contemporânea como hibridismo, crioulização, transculturação, mestiçagem, heterogeneidade permite uma incorporação crítica dessas teorizações, ou, ainda, uma adequação dessas contribuições de modo criativo e crítico, considerando realidades tão distintas quanto as de países da América, como Brasil, Chile, Caribe, México, ou de África, como Angola, Cabo Verde, Moçambique, Guiné Bissau, São Tomé e Príncipe com as situações de Espanha e Portugal permeando intersecções. 
Lançado no ano passado pela Arte\&Ciência, na Coleção Via Atlântica, em suas 252 páginas ensaiam-se exercícios de crítica e leitura com a formulação de perspectivas "voltadas para a apreensão da rede de contatos entre os espaços situados fora dos centros hegemônicos, com atenção posta na natureza das respostas que a literatura, enquanto fato cultural e fenômeno estético, necessariamente apresenta”, como notam as organizadoras Rita Chaves e Tania Macêdo.

Os títulos dos grupos de ensaios já dão uma idéia da dimensão das preocupações que se verificarão ao longo do livro. No primeiro grupo, "Hibridismo, crioulização, transculturação: conceitos e noções em movimento” as ensaístas detêm-se de forma sistemática em problemas de ordem conceitual e histórica, apontando para a necessidade de uma adaptação desses conceitos às diversas realidades de cada local. Ana Pizarro, Professora da Universidade do Chile, que muito vem contribuindo para as reflexões sobre a situação da América Latina, trata, em seu ensaio, das múltiplas mudanças ocorridas na década de 60 e implicadas nas seguintes que propiciam o surgimento de reivindicações relativas à pluralidade, isto é, a autora defende a idéia de que para se compreender as trocas, é necessário incorporar o contexto, o qual origina uma reflexão tanto das ciências sociais quanto da teoria da cultura da América Latina. Pizarro inicia suas instigantes argumentações, abrindo-nos campos para conhecermos melhor nosso continente e mais a respeito de nós mesmos, pelos avanços tecnológicos das décadas de 70 e 80, que tornam hoje necessário incorporar à perspectiva da comunicação as análises do novo contexto internacional, de onde procedem as articulações e orientações que dão lugar às trocas nos sistemas de construção de sentidos de nossas culturas atuais. Diva Damato parte da idéia de um mundo globalizado e em contatos múltiplos, que, se por um lado, em sua gana expansionista, transformou em mão-deobra escrava grandes civilizações, por outro propiciou o encontro de povos e culturas e os fenômenos da mestiçagem, do hibridismo cultural, da cultura crioula, que tornam possível a pequenos países tornarem-se visíveis, como a pequena ilha da Jamaica, mas suas reflexões se deterão no Caribe francês e sua história e literatura, bastante próximas das do Brasil, como compara. Elisalva Madruga Dantas em seu ensaio discute a existência de um viés contra-cultural que aproxima literaturas africanas, com destaque para a angolana e caboverdeana, da literatura brasileira, sobretudo de poetas e escritores 
das décadas de 20 e 30 do século XX. Marli F. Scarpelli também discute os conceitos, confrontando-os a partir de modelos de "transculturação narrativa”, em textos de escritores latino-americanos como João Guimarães Rosa e José Maria Arguedas, em que, segundo a autora, uma terceira margem constitui-se em espaço simbólico, fundadora da alteridade com que o discurso latino-americano se inscreve na modernidade pós-colonial.

As teorizações sobre a heterogeneidade vão sendo pensadas criticamente, impedindo uma incorporação das novas idéias sem o crivo da crítica e da adaptação consciente às necessidades de cada local.

Os ensaios do segundo grupo confrontam os conceitos em exercícios de leitura. Luis A. Brandão Santos recorre a obras que, em seus projetos escriturais, apesar de reconhecidamente críticos, incorporam procedimentos literários como o da crítica Argentina Beatriz Sarlo, com Instantáneas, e da romancista chilena Diamela Eltit, com Emergencias. Maria Ester Macieltrata da intersecção de bestiários do passado (Aristóteles, História dos animais; Plínio, o Velho, nos 37 livros de sua História Natural) e do presente (como Jardim Zoológico, de Wilson Bueno), no espaço atual das letras e das artes latino-americanas, buscando verificar em que medida as figurações zoológicas do presente revêem criticamente as imagens construídas pelos primeiros colonizadores em torno da América Latina. Maria Nazareth S. Fonseca retoma aspectos de exposições e mostras realizadas por ocasião das comemorações dos 500 anos do Brasil, que revelaram meandros ainda desconhecidos da memória brasileira, híbrida, mestiça. Em "Hibridismo e o gênero epistolográfico", Nádia B. Gotlib, partindo da constatação de que a carta traduz um contexto híbrido por natureza, examina como a mistura de espaços funciona no corpo do texto de correspondências do século XIX, quando havia a prática diária da correspondência.

A discussão sobre os conceitos presentes na crítica contemporânea leva a reflexão para o campo da "diversidade, circulação de formas e processos literários”, em que Benjamin Abdala apreende a unidade na diversidade pelo exame do problema da "globalização e identidade", colocando a "bacia cultural ibero-afro-americana em perspectiva”. Horácio Costa centra sua atenção na poesia mexicana e brasileira modernas, percebendo interfaces na diversidade. Em “Estudos literários: diversidade cultural”, Maria dos Prazeres Mendes parte do princípio de que "todo conhecimento tem um 
enraizamento social e histórico” e, passando pelas configurações de suas etapas, propõe a leitura da realidade nacional de modo abrangente, permitindo-se pensar que o texto literário pode representar, dentre outras, "condições de sua própria produção e existência”. Já Maria Luiza Scher Pereira percorre, pelos "Modos de viajar, modos de narrar. Modos de ler, modos de escrever”, narrativas de Rubem Fonseca, Nélida Piñon e Clarice Lispector, que relêem nos anos 60 e 70 textos da tradição da ex-metrópole, confrontando-os pela leitura que desmonta a engrenagem que os constrói.

O quarto grupo de ensaios é composto por reflexões sobre o encontro das literaturas de países de língua portuguesa, que deu origem à área de Estudos Comparados de Literaturas de Língua Portuguesa da Faculdade de Letras da USP e depois ao GT homônimo da ANPOLL. Os autores visitam Cabo Verde, Goa, Moçambique, Angola e Brasil. A situação da literatura de Cabo Verde é examinada nos ensaios de Helder Garmes e Rubens Pereira dos Santos. Garmes contribui para a ampliação do campo dos estudos comparados ao chamar a atenção para uma identidade mestiça no confronto da noção de miscigenação em duas obras de meados do século XIX, O escravo, de José Evaristo de Almeida, e Os brâmanes, de Francisco Luís Gomes (ambientado em Fizabad, norte da Índia), as quais inauguram o gênero romance em Cabo Verde e Goa, respectivamente, e cujas tramas envolvem conflitos raciais e culturais. Já o de Rubens, partindo da análise do movimento da negritude - conceito que explora criticamente na confrontação com a produção de autores caboverdianos - historia e analisa a formação de uma sociedade mestiça e de uma literatura crioula.

Os ensaios de Rita Chaves e Tânia Macedo, pesquisadoras de África de Língua Portuguesa desde a década de 80 e organizadoras de Literaturas em movimento, historiam nossas trocas culturais à luz da literatura. Enquanto Rita Chaves examina a "periferia no centro do território poético" de Angola e Moçambique nos anos 60, contextualizando o cenário em que os poetas António Jacinto e Viriato da Cruz, de Angola, e José Craveirinha, de Moçambique, "fizeram de sua obra um espaço de encontro para aqueles que permaneciam condenados à exclusão, mesmo no campo do imaginário”, Tania Macêdo, numa perspectiva também comparativista não só de literatura como de sociedade, vê os "malandros" - conceito que define bem, desmontando imagens pré-concebidas - como figura híbrida que freqüenta nossa literatura e morros, assim como textos e ruas de Luanda, em Angola. 
Embora possa notar-se um eixo em torno do qual Literaturas em Movimento giram, as trocas culturais estabelecidas entre Brasil e países africanos de língua portuguesa, o livro vai além dessas importantes discussões.

Ampliando ainda mais o salutar debate, os estudos do Grupo de Trabalho da ANPOLL encaminham-se, partindo de contribuições antes dispersas, para os estudos culturais latino-americanos, de natureza híbrida e marcados pela "heterogeneidade multitemporal". A preocupação da América Latina com as "condições" (implicados no conceito: hibridismo, ser periférico, caráter nacional, globalização, colonialismo, dependência...) da modernidade e da pós-modernidade, tem sua fundamentação na desigualdade em relação aos centros hegemônicos (onde a desigualdade também impera) e é certo que essas "condições" estarão, como já estão, norteando o pensamento crítico latino-americano nos próximos anos. Literaturas em Movimento já vem corrigindo as distorções estabelecidas pelas abordagens hegemônicas com a diversidade de suas criteriosas críticas.

As trocas culturais efetivam-se de modo veloz e o mundo acadêmico acompanha o movimento espraiando suas reflexões críticas e literárias desde o México, Caribe, passando por países da América Latina e das suas ex-metrópoles na Europa, indo para a África de Língua Portuguesa, chegando a Goa na Índia e... tudo neste livro que amplia e relativiza nossas noções de local. 